be a means of gaining experience in fields of practice particularly useful to recently qualified medical men.

During the past fifteen years or so great strides have been made in medicine and surgery, but I believe in no departments have there been more improvements than in the medical administration of our Poor-law institutions.

I am, Sirs, yours faithfully,

$$
\text { July 26th, 1887. ARTHUR FflintoFF MickLe, M.B. }
$$

\section{"SUBSTANTIVE VERSUS HONORARY RANK."}

To the Editors of Thes LANCET.

SIRs,- So many sensible letters, supported by your favourable comments, have appeared in THE LANCET against honorary rank for medical officers in the army, that nothing more seemed necessary to be said. Having, however, just heard from a friend that a medical contemporary supports the idea of honorary rank, and teems with letters in favour of it, I venture to suggest that the wishes of the majority of medical officers are not represented by these letters. Naturally, those wanting honorary rank write; while the contented ones remain, as a rule, quiet. But there is, I believe, no doubt that, if there were any danger of honorary rank being given to us, a large majority of the medical staff and of the Indian Medical Service would support Mr. Stanhope's statement in the House of Commons, that they had no wish for "titles so dissociated from the duties of their honourable profession," and would protest in the words of your correspondent, "Army Surgeon," against becoming "the laughing stock of the army."

I am, Sirs, yours faithfully,

S. L. DoBIe,

Kamptee, India, July 3rd, 1887 Surgeon-Major, 4th Madras Cavalry.

\section{VAGINAL HYSTERECTOMY.}

To the Editors of THE LANCET.

SIns,-Dr. Braithwaite's interesting paper in your issue of July 23 rd contains much controversial matter. I would first congratulate him on his success, and then, briefly as possible, touch on certain of his statements as regards the best method of operating. Not having a copy of THE LANCET before me at the time of writing, I must rely on my memory, which I trust will be found accurate.

Dr. Braithwaite disapproves of the use of instruments for checking hæmorrhage from the vessels in the broad ligament, and deprecates any attempt to secure them without retroverting the uterus. My experience is quite opposed to this, and having operated on two cases, and seen a few others done, I have no hesitation in saying that with the use of properlyshaped strong forcipressure forceps with a firm catch the operation is materially shortened and bleeding quite safely controlled. In my cases the body and fundus were large, hence the broad ligaments were of a greater vertical depth, and my forceps would only clamp their lower two-thirds; but when the body is of the normal size the forceps act admirably, and the operation is less difficult. With these instruments there is no fear of any slipping of ligatures or risk of secondary hæmorrhage from their ulcerating through the coats of the vessels. Dr. Braithwaite disapproves of the use of sponges. I can only say that in my last case, which made an admirable recovery, and which was a case of cervical cancer complicated with pregnancy, I found that a soft flat sponge, folded, with a strong carbolised silk ligature tied round its middle and introduced into Douglas's cavity, was an excellent means of absorbing the blood which came from the uterine side after separating the uterus. When removed at the end of the operation, it brings the peritoneal and mucous surfaces outwards and into contact, and they soon unite; hence, in my view, as in that of many others, there is no need for suturing these surfaces. A large drainage tube with capacious holes should be inserted for a couple of days, and syringing commenced at the end of twenty-four hours, and done at least three times daily or of tener according to the amount and condition of discharge. This is very important. Dr. Braithwaite seems to contradict himself with reference to the propriety of first removing the diseased cervix. Unless the mass be large there is no need for this, as the peritoneum need not be infected in the operation with forceps, but in retro- or ante-version with ligature it may be. There are other points in the operation which I must leave to another occasion, but I feel sure Dr. Braithwaite will agree with me when 1 say that in the interest of patients I wish he had insisted that no one should attempt the operation without having practised it on the cadaver a fev times, and without having seen it done on the living.

With regard to the indications for the operation, its mortality, and its comparison with supra-vaginal excision of the cervix, I am compelled by the most recent information to differ from him and other writers on the subject. On the matter of so-called recurrence, which really means an incomplete operation, we must all wait for time to decide as regards total extirpation; but as Schroeder's cervical excision is at best but a partial operation, and has a mortality of at the best 7 per cent, and an all-round mortality several points higher, and as recurrences have been too frequent, I think every careful surgeon would agree that the mortality is far too high for any partial proceeding, and the recurrence is what he would expect. Now, the most recent mortality results of the complete operation are nil-i.e., that two operators have had a series of fifteen or twenty cases without a death,--and I see no reason why experienced operators should not obtain similar results in this country; but even if the expert and all-round mortality were, with recent improved modes of operating, equal to the best results of Schroeder's operation, i should elect the complete operation, as in properly previously examined cases and those proper for the method there is far greater prospect of a permanent cure by the radieal plan. To take the pathology of Ruge and Veit (which is some years old, and needs confirmation) as a basis on which to select an operation can only lead to disappointment, for we hardly ever see cases early enough to feel at all sure that we can get well above the disease; and even if it were proved to demonstration that cancer of the vaginal portion always spreads outwards to the lymphatics in the broad ligament, and rarely, or never, upwards along the canal, I hold that the complete operation would enable us to well remove the diseased parte of the broad ligaments in eaces which are not too far advanced for any operation. In those extremely rare cases which are seen early enough for Schroeder's operation, there can be no comparison between it and the complete one, for these rare cases are suitable for the former and not for the latter; but in the majority of cases, as we first see them, Schroeder's operation, with its high mortality and frequent recurrence (through incompleteness) is, in my opinion, out of court. The ordinary amputation of the cervix by the écraseur and other means is only admissible in cases of papilloma, and even these have been known to return. So that in dealing with ordinary cases of cancer as we see them, whether of the vaginal portion, cervical canal, or body, it seems to me that elytro-hysterectomy is the best proceeding. - I am, Sirs, yours truly, -Grosvenor-street, w., July, 1887.

II. A. REEVES

\section{THE THERAPEUTICAL SOCIETY.}

\section{To the Editors of THe LaNCET.}

SIRs,-At a meeting held last Friday by the kind permission of Dr. Milner Fothergill at his house, the following gentlemen were elected as Executive Council of the above Society, with power to add to their number:-Dr. Milnep Fothergill, M.R.C.P.L.; Mr. Haward, F.R.C.S. Eng.; Dr, Stretch Dowse, F.R.C.P.E. ; Dr. Prosser James, M.R.C.P.L. ; Dr Saundby, F.R.C.P.L.; Dr. Campbell ; and Dr. Illingworth.

A discussion arose, after the reading of a paper on the advantages of this Society, as to the admission as members of all registered general practitioners; and it was finally decided that, as the basis of the Society was to be distinctly "unsectarianism," the following should be the rule for eligibility for admission : "That all qualified medical practitioners shall be eligible for membership provided that they have not already avowedly pledged themselves to any exclusive line of therapeutics." If all gentlemen, therefore, who have already sent in their names for membership, who cannot agree to this rule, will kindly write me a card withdrawing from the Society, [ shall be much obliged; at the same time I trust that they will be "few and far between." It was felt by the Council that as an "unsectarian" Society it would be destructive to admit as members any holding strongly biased views with regard to therapeutics. This Society is founded for "investigation of all methods of medical treatment now existing, or which may afterwards be introduced," and therefore it stands as a reasonable pro- 